\title{
Síndrome respiratorio agudo severo (SRAS).
}

\author{
GARCIA APAC Coralith * , MAGUIÑA VARGAS Ciro* GUTIERREZ RODRIGUEZ Raul \&\&.
}

\section{RESUMEN}

En esta revisión actualizada presentamos los principales aspectos históricos, epidemiológicos, clínicos, terapéuticos y medidas de control y prevención de esta nueva enfermedad conocida como SRAS ( Síndrome Respiratorio Agudo Severo), que se ha considerado como la primera enfermedad infecciosa de origen viral epidémica del siglo XXI afectando principalmente áreas de China, incluyendo Taiwán y Hong Kong, así como Vietnam, Singapur y Canadá ( Toronto).. El agente viral causante de esta enfermedad es un nuevo coronavirus. El tratamiento mas efectivo aun no ha sido definido.

\section{PALABRAS CLAVES: SRAS, Coronavirus, Neumonía Severa}

\section{INTRODUCCION}

En los últimos treinta años han aparecido nuevas enfermedades, a las que se le han denominado "enfermedades emergentes", ejemplo de ellas son: la enfermedad de los Legionarios, el SIDA, las enfermedades hemorrágicas severas como el Ebola, Guanarito, Sabia, Hantavirus, entre otras (1).

En este siglo se ha descrito por primera vez una nueva enfermedad infecciosa de origen viral, la que se ha denominado Síndrome Respiratorio Agudo Severo (SRAS). En noviembre del 2002, un hombre de negocios falleció de una misteriosa enfermedad respiratoria aguda en la provincia de Guangdong (China Popular), la cual cuenta con 75 millones de habitantes.

Posteriormente aparecen cientos de casos similares en esta misma provincia, que fueron causa de numerosas muertes, pero lamentablemente permanecieron sin notificación científica. Es recién, en Febrero del 2003, cuando los médicos de Hong Kong difunden a la comunidad científica la existencia de una enfermedad respiratoria desconocida de comportamiento epidémico en el continente asiático. Un médico procedente de Guangdong, que presentó este proceso respiratorio febril agudo severo, había estado hospedado en el noveno piso de un hotel de Hong Kong y doce de otros huéspedes del mismo piso enfermaron días después. Todos ellos se convirtieron posteriormente en los casos índices al regresar a Vietnam, Singapur y Canadá $(2,3)$.

El SRAS fue reconocido por primera vez el 26 de Febrero de 2003 en Hanoi, Vietnam. La posterior aparición de casos a Europa y América del Norte produjeron nuevos brotes en estos países, por ello el 12 de marzo del 2003, la Organización Mundial de la Salud (OMS) declaró la alerta mundial y bautizó a esta nueva enfermedad con el nombre de Síndrome Respiratorio Agudo Severo ("SRAS"), y definió los casos sospechosos y probables.

Gracias al esfuerzo de varias comunidades científicas de diferentes países, dos semanas después se identificó al agente infeccioso viral. Hasta el 17 de Junio la OMS ha notificado 8,464 casos, 799 de ellos fatales, en 29 países de Asia (92\% de estos casos en China), Europa, África, Norte y Sudamérica. En esta última, sólo se

\footnotetext{
* Departamento de Enfermedades Transmisibles y Dermatológicas (DETD), Hospital Nacional Cayetano Heredia

\&\& Instituto de Medicina Tropical Alexander Von Humboldt, Universidad

Peruana Cayetano Heredia
} 
han reportado 3 casos en Brasil y un caso en Colombia (2,3).

El mayor número de casos a nivel mundial fue reportado entre la segunda quincena de marzo y la primera quincena de mayo del 2003. A raíz

de esta epidemia y la alarma mundial, en Vietnam las autoridades sanitarias y políticas en forma precoz adaptaron medidas estrictas de cuarentena y control sanitario de los casos y contactos, logrando ser el primer país en controlar esta nueva epidemia. Posteriormente otros países han logrado controlar esta nueva enfermedad.

\section{AGENTE INFECCIOSO}

$\mathrm{Al}$ inicio se pensó que el SRAS era causado por un picornavirus y luego un neumovirus, pero posteriormente en forma rápida y paralela, científicos de diversos países, identificaron el verdadero agente, un nuevo virus perteneciente al género Coronavirus (4) Este género fue descrito por primera vez en 1965 por Tyrrell y Bynoe, como semejante al virus de la bronquitis de los pollos (5), y su naturaleza citopática por Hamre y Procknow al ser aislado en estudiantes de medicina que padecían de resfríos (6). Se estableció el término coronavirus (por el prefijo corona, que denota dicha apariencia en las proyecciones estructurales de su superficie) para dar significado a este nuevo género viral (7) . Se considera como el principal agente viral veterinario que afecta el tracto respiratorio y gastrointestinal, así como el sistema nervioso central y el riñón, y durante los últimos quince años se han descrito partículas coronavirus símil en materias fecales humanas (8) .

Las muestras de pacientes que cumplían con la definición de caso de SRAS fueron enviadas al Centro de Prevención y Control de Enfermedades (CDC) por colaboradores de Vietnam, Singapur, Tailandia, Hong Kong, USA y Canadá como parte de la investigación del agente etiológico (4). Las características citopatológicas fueron observadas en las células Vero E6 del inóculo de una muestra de hisopado faríngeo. A través de la microscopía electrónica, fueron evaluadas las características ultraestructurales, encontrándose que estas eran similares a las de los coronavirus.

Además, se demostró por análisis de inmunohistoquímica e inmunofluorescencia, que eran reactivos contra anticuerpos policlonales del grupo I de estos virus; pero a través de la técnica de PCR, se pudo determinar que la secuencia de nucleótidos era diferente a la de los coronavirus conocidos. Posteriormente se implementó técnicas de ELISA e inmunofluorescencia para la detección de anticuerpos séricos específicos (4). En base a estos hallazgos, se confirmó la sospecha que un nuevo virus perteneciente a la familia de los coronavirus era el agente asociado a SRAS. ¿Cómo un agente perteneciente a una familia de virus que suele manifestarse como resfrío común en el hombre podía ahora relacionarse con una enfermedad tan severa? Se conoce que los coronavirus producen cuadros respiratorios y gastrointestinales severos en los animales, por lo que no es difícil aceptar la hipótesis de que un coronavirus inicialmente originado en un animal mutó o recombinó, permitiendo infectar al hombre, producir enfermedad y pasar de persona a persona.

Se viene realizando investigaciones tanto en animales salvajes como en los domésticos para reforzar esta teoría $(9,10)$. Se ha encontrado un coronavirus muy similar al asociado a SRAS en animales salvajes que se consumen en los mercados de Guandong (9), aunque se desconoce si estos animales serían los reservorios naturales o han sido infectados a partir de otro animal. Por otro lado se conoce que las cucarachas y las ratas actúan como huéspedes pasivos, ingiriendo y eliminando el virus, pero sin presentar ninguna evidencia serológíca ni histopatológica de infección. Se ha propuesto que el gato doméstico jugaría algún rol en la transmisión del nuevo coronavirus. Si se confirma que el gato puede infectarse, este sería uno de los responsables de introducir al virus dentro de las casas. Los científicos han identificado al gato como potencial modelo sin embargo hasta el momento el único modelo animal reconocido es el mono macaco (10).

\section{HISTORIA NATURAL DE LA ENFERMEDAD}

Se considera que la principal forma de transmisión es la vía aérea. Se ha detectado mas de 100 millones de copias de ARN viral en el esputo de pacientes en la fase aguda (11). Por otro lado, se conoce que el virus puede permanecer en el medio ambiente alrededor de 3 horas. Se han encontrado también partículas vírales en las heces de pacientes convalecientes (11), lo que apoya junto a otras evidencias, la posibilidad de transmisión fecal-oral. Después de un periodo de incubación de 3 a 10 días, el paciente presenta síntomas en forma súbita. No se conoce el período de transmisibilidad, tampoco la susceptibilidad e immunidad.

Fiebre, es un síntoma referido casi en el $100 \%$ de los pacientes en las series reportadas $(12,13,14)$. Siguen en orden de frecuencia: tos, mialgias, dísnea, cefalea, malestar general, escalofríos y diarrea (esta última reportada hasta en el 23\% de los casos) (14). En el examen físico es frecuente el hallazgo de crepitantes en campos pulmonares. En los exámenes de laboratorio los hallazgos más prevalentes son linfopenia, 
trombocitopenia, proteína $\mathrm{C}$ reactiva alta, elevación de las transaminasas, elevación de las deshidrogenasa láctica así como trastornos electrolíticos, especialmente hiponatremia $(12.13,14)$. La hipoxemia puede ser severa en algunos pacientes, cerca de la cuarta parte de ellos desarrollan insuficiencia respiratoria. En cuanto a los hallazgos radiográficos, según una serie de 144 casos descritos en Canadá (14), al momento del ingreso se observaron infiltrados unilaterales y bilaterales, en el $46 \%$ y $29 \%$, respectivamente. Del $25 \%$ de pacientes que presentaban una radiografía normal, el 58\% de ellos, presentó infiltrados unilaterales o bilaterales, durante la evolución.

La mayoría de los pacientes con SRAS son adultos previamente sanos, entre 25 y 70 años con una media de 54 años. Los brotes en Toronto y Hong Kong (12, 14) han involucrado a adultos jóvenes, con una edad que oscila entre 39 y 42 años y en ambos brotes alrededor de $50 \%$ de pacientes eran trabajadores de salud. Fue necesario la admisión a una unidad de cuidados intensivos en 21 a $38 \%$ de los casos, y del 14 al 38\% necesitaron ventilación mecánica. La mortalidad reportada ha sido entre 4 y $6 \%$. No se han reportado casos fatales en USA. Sin embargo existe una diferencia importante entre las tasas de mortalidad entre las series reportadas en la China y Canadá (3.6\% vs $5.6 \%$, respectivamente).

Los análisis estadísticos con modelos multivariados en las series reportadas, establecen la identificación de algunos factores asociados a mal pronóstico, entre ellos fundamentalmente la edad mayor de 60 años y la comorbilidad (14).

\section{TRATAMIENTO}

La mayoría de pacientes han recibido antibióticos diversos (incluyendo una cefalosporina de tercera generación y un macrólido, entre otros), sin mayor variación en la evolución. En Singapur, Hong Kong, Guangdong y Canadá se ha utilizado una combinación del antiviral ribavirina con corticoides a dosis altas (12, 13, 14). Existe en la actualidad gran controversia en cuanto a la eficacia de este esquema terapéutico, sin embargo en ausencia de otro esquema alternativo probablemente se siga utilizando.

La ribavirina es una droga que puede ser tóxica en algunos personas. Cerca del $50 \%$ de los pacientes experimentan el descenso de la hemoglobina de por lo menos $2 \mathrm{~g} / \mathrm{dl}$ y en $66 \%$ de estos pacientes se evidencia hemólisis, con la elevación de la bilirrubina indirecta (14). Se reconoce también el incremento en el riesgo de desarrollo de arritmias cardiacas. Por otro lado, su eficacia contra el virus del SRAS es desconocida (15). Se sabe que es efectiva contra otros virus como el virus sincitial respiratorio, el cual es similar al metapneumovirus, aislado inicialmente en Hong Kong y que se creyó era el agente causal de SRAS. Además, in vitro, la concentración inhibitoria de la ribavirina contra el nuevo coronavirus es \pm 30 , valor mucho más alto que el nivel usual (entre 1 y 5) para otros virus asociados a enfermedades respiratorias. Es también conocido su efecto teratogénico, por lo cual no se recomienda su uso en el primer trimestre del embarazo.

En cuanto al uso de corticoides, tampoco se ha llegado a un acuerdo. Los que apoyan su uso (13) argumentan que es necesario suprimir la respuesta inflamatoria la que es mediada por una serie de citoquinas y de esta manera detener la progresión de la enfermedad pulmonar. Los que están en contra (16) refieren que en base al manejo del síndrome de distress respiratorio agudo, en donde el uso de corticoides ha sido controversial, estos no deberían ser incluidos como parte del manejo de SRAS. Existe alrededor de $10 \%$ de pacientes que no responden en forma favorable al esquema de ribavirina más corticoides. En estos pacientes se ha intentado la inmunización pasiva con plasma de pacientes en estado de convalecencia, que contiene títulos altos de anticuerpos antivirus. En este grupo de pacientes también se ha usado plasmaferesis, inmunoglobulina y pentaglobulina. La eficacia de estas intervenciones terapéuticas aún no ha sido evaluada.

Se ha propuesto el uso de esquemas profilácticos con ribavirina oral para trabajadores de salud expuestos a pacientes con SRAS, lo que ha generado también gran controversia, por lo que su uso no ha sido muy difundido.

\section{CONTROL}

La estrategia para el control de esta nueva enfermedad esta basada en tres pilares fundamentales: la detección temprana del caso, su aislamiento y el manejo de los contactos $(2,3)$.

La mejor estrategia

para limitar la transmisión dentro del hospital es el aislamiento. Desde el triaje, el paciente debe ser evaluado en un ambiente aislado y debe usar una mascarilla que filtre el aire espirado. El personal de salud que lo atienda debe usar mascarilla, lentes protectores y debe lavarse las manos antes y después de atender al paciente. Debe recordarse que el estetoscopio y otras herramientas son potenciales rutas de transmisión. El uso de desinfectantes debería estar disponible a 
concentraciones adecuadas. Si el paciente cumple con los criterios de caso sospechoso o probable debe ser hospitalizado y aislado, idealmente en una habitación a presión negativa o en su defecto una habitación simple con una cama y baño propio. El paciente no debe salir de la habitación, y si lo hace debe usar una mascarilla.

Debe prestarse particular atención a las intervenciones que generen aerolización como nebulizaciones, fisioterapia respiratoria, broncoscopía y gastroscopía.

El lavado de manos antes y después de la atención del paciente sigue siendo una intervención crucial. Se puede usar desinfectantes de piel basados en alcohol.

La limpieza de la habitación debe hacerse con desinfectantes de conocida acción antiviral. Todo el personal involucrado incluyendo el personal de limpieza así como las visitas (las cuales permanecerán restringidas) deben usar un equipo de protección personal que incluya el uso de mascarilla, P99 o P100 ( que filtra el 99 y el $99.97 \%$ del aire espirado, respectivamente), lentes protectores, guantes y mandilón. Todo el personal debe estar entrenado para mantener las medidas de control de infección en el cuidado del paciente con SRAS. El paciente permanecerá hospitalizado hasta la etapa de convalecencia, cuando permanezca afebril, no presente tos, los exámenes de laboratorio inicialmente anormales tiendan a normalizarse y los hallazgos radiográficos tiendan a resolverse (2).

\section{CONTACTO CERCANO}

La detección y control de los contactos es una de las medidas de control más efectivas. Se define como contacto cercano a toda persona que este en riesgo de desarrollar SRAS debido a la exposición de un paciente con esta enfermedad, entendiéndose como exposiciones de riesgo el vivir, cuidar o tener contacto directo con secreciones respiratorias u otros fluídos corporales de un paciente con SRAS $(2,3)$. Dependiendo si el caso índice fue sospechoso o probable, el contacto también se definirá como contacto de caso sospechoso o probable, respectivamente. El contacto casual con un paciente con SRAS no se considera una exposición de riesgo. Los contactos deben ser educados acerca de las diferentes características de la enfermedad haciendo énfasis en el reconocimiento de la fiebre que suele ser el síntoma mas frecuente y precoz. El contacto de caso probable debe permanecer en casa voluntariamente por espacio de 10 días. Se le debe realizar una vigilancia activa mediante la visita diaria de un trabajador de salud.
En cambio, el contacto de caso sospechoso, puede continuar realizando sus actividades fuera de casa pero comunicándose diariamente por teléfono con un servicio de salud.

¿Qué hacer a nivel internacional? Debe educarse a los viajeros internacionales sobre el reconocimiento de los principales síntomas de SRAS: fiebre, tos y/o disnea.

Para prevenir la diseminación de SRAS los viajeros deben ser evaluados al salir de un área de transmisión reciente a través de un cuestionario y la toma de temperatura. Hasta el 17 de Junio, esta recomendación debe llevarse a cabo en Toronto (Canadá), Beijing, Hong Kong y Taiwan (China). No hay restricciones en cuanto al transporte de alimentos o animales desde estas áreas $(2,3)$. Si el viajero al regresar a su país, presenta algunos de los síntomas descritos dentro de los 10 días de su llegada debe solicitar atención médica. Desde abril del 2003 la OMS/CDC ha recomendado posponer los viajes que no sean esenciales a las diferentes áreas de transmisión de SRAS. Esta recomendación es reevaluada día a día. Hasta el 17 de junio, la única localidad en la que se sigue manteniendo esta recomendación es en Beijing (China).

\section{CONCLUSIONES}

Esta nueva enfermedad producida por un virus del género coronavirus, ha sido la primera enfermedad viral de tipo epidémico que en un tiempo récord ha sido diagnosticado, gracias a la colaboración de los científicos de varios países. Así mismo, en forma extraordinaria se ha logrado desarrollar el genoma del virus y con medidas de control tan sencillas y antiguas como la cuarentena, se ha podido controlar y evitar la diseminación en muchos lugares. Si bien ha causado pánico y zozobra a nivel mundial, en comparación con el virus de la inmunodeficiencia humana, tuberculosis, malaria e influenza, han sido relativamente pocos los casos de SRAS así como un limitado número de muertes. Sin embargo, aún no se puede predecir cual será el curso de esta nueva enfermedad ni el impacto global que genere. Pero desde ya sabemos que el SRAS ha cambiado la forma de practicar la medicina de hoy.

Las mascarillas tendrán que ser usadas por el paciente y el doctor durante la atención médica y cada una de éstas a su vez se convertirán en un riesgo potencial.

Una vez más la vocación y el interés de ayudar superaran el temor de enfermar y morir; de hecho, cientos de trabajadores de salud superaron el miedo y 
hoy se cuentan entre los héroes.

\section{Correspondencia:}

Coralith García Apac

5B-101 Unidad Vecinal del Rimac

03345@upch.edu.pe

\section{RESUMEN BIBLIOGRAFICO}

1. Chin, J. El control de las enfermedades transmisibles. Publicación cientifica y tecnica 581. XVII Edicion. Organización Panamericana de la Salud. 2001

2. www.cdc.gov/ncidod/sars

3. www.who.int/csr/sars

4. Ksiazek T, Erdman D, et al. A novel coronavirus associated with severe acute respiratory syndrome. The New Engl J of Med 2003;348(20):1953-1966

5. Tyrrell DA, Bynoe ML. Cultivation of a novel type of common-cold virus in organ cultures. British Med J 1965;1:1467-70

6. Almeida JD, Tyrrell DA. The morphology of three previously uncharacterized human respiratory viruses that grow in organ culture. J Gen Virol 1967;1:175-78

7. McIntosh K, Dees JH, Becker WB, et al. Recovery in tracheal organ cultures of novel viruses from patients with respiratory disease. Proc Natl Acad Sci USA 1967;57:93340

8. Holmes KV, Lai MC. Coronaviridae and their replication. En: Fields B, Knipe D, Howley P eds. Fields Virology. $3^{\text {rd }}$ ed. Philadelphia. Lippincot-Raven 1996:1075

9. Cyranosky D, Abbott A. Virus detectives seek sources of SARS in China s wild animals. Nature 2003; 423(2939):467

10.Abbott A. Pet theory comes to the fore in fight against SARS. Nature 2003; 423(6940):576

11.Drosten C, Gunther S, et al. Identification of a novel coronavirus in patient with severe acute respiratory syndrome. The New Engl J of Med 2003;348(20):19671976

12.Lee N, Hui D, et al. A major outbreak of severe acute respiratory syndrome in Hong Kong. The New Engl J of Med 2003;348(20):1986-1994

13.Tsang H, Ho P, et al. A cluster of cases of severe acute respiratory syndrome in Hong Kong. The New Engl J of Med 2003;348(20):1977-85

14.Booth C, Matukas 1, et al. Clinical features of short term outcome of 144 patients with SARS in the greater Toronto area. JAMA 2003; 289 (2): 2801-2805

15.Koren, G. King S, et al. Ribavirina in the treatment of SARS: a new trick for an old drug. CMAJ 2003; 168(10): 1289-1292

16.Oba Y. The use of corticosteroids in SARS. The New Engl J of Med 2003; 348 (20):2034-2035. 